\title{
SATISFAÇÃO NO ATENDIMENTO: UM ESTUDO NA EMPRESA JM ALARMES EM GUARAPUAVA/PR
}

\section{CUSTOMER SATISFACTION: A STUDY IN THE COMPANY JM ALARMS IN GUARAPUAVA / PR}

\author{
Roseli de Oliveira Machado \\ Mestre em Administração pela Universidade de São Paulo - USP \\ Professora do Departamento de Administração da Universidade Estadual do Centro-Oeste do \\ Paraná - UNICENTRO \\ E-mail: roseli_machado@yahoo.com (Brasil)
}

\section{Juliane Sachser Angnes}

Doutora em Educação pela Universidade Federal do Paraná - UFPR

Professora do Departamento de Secretarido Executivo da Universidade Estadual do Centro-Oeste do Paraná - UNICENTRO

E-mail: julianeangnes@gmail.com (Brasil)

\section{Marcela Elise Bordinhão Pimentel}

Bacharel em Secretariado Executivo pela Universidade Estadual do Centro-Oeste do Paraná UNICENTRO

E-mail: elisemarcela@hotmail.com (Brasil)

\section{Luciano Mazur}

Bacharel em Secretariado Executivo pela Universidade Estadual do Centro-Oeste do Paraná UNICENTRO

E-mail: luciano_mazur@yahoo.com.br (Brasil) 


\title{
SATISFAÇÃO NO ATENDIMENTO: UM ESTUDO NA EMPRESA JM ALARMES EM GUARAPUAVA/PR
}

\section{RESUMO}

Diante da competitividade imposta pelo mercado, a satisfação no atendimento torna-se um dos aspectos essenciais para o sucesso dos negócios, e por isso, grande parte das empresas visa ampliar a qualidade na oferta dos produtos e serviços. Focado nesta concepção, este estudo apresenta resultados parciais de uma pesquisa realizada no ano de 2011 que se propôs a identificar a satisfação no atendimento prestado pela empresa JM Alarmes, localizada na cidade de Guarapuava Paraná. Trata-se de uma pesquisa de campo exploratória que utilizou a pesquisa bibliográfica, o questionário em formato likert, a pesquisa documental, a observação participante e o diário como principais técnicas de pesquisa. O questionário de pesquisa foi aplicado em uma amostra composta por 71 clientes no período de 1 a 30 de setembro de 2011, visando diagnosticar o nível de satisfação em relação ao atendimento prestado pela empresa. Dessa forma, foi possível avaliar as percepções dos clientes, apontar as deficiências em relação ao atendimento prestado, ao mesmo tempo em que demonstrou aos colaboradores a relevância em se desenvolver um atendimento voltado às necessidades dos clientes e não apenas o cumprimento de metas.

Palavras-chave: Qualidade no Atendimento; Satisfação; Atendimento ao Cliente.

\section{CUSTOMER SATISFACTION: A STUDY IN THE COMPANY JM ALARMS IN GUARAPUAVA / PR}

\begin{abstract}
Given the competitiveness imposed by the market, satisfaction in service becomes a key aspect to the success of a business, and therefore most companies are aimed at enhancing quality in the provision of products and services. Focused on this concept, this study presents partial results of a survey conducted in 2011with the purpose of identifying satisfaction in service provided by the company JM Alarms, located in Guarapuava - Paraná. This is an exploratory field study that used a literature research, the questionnaire in Likert format, documentary research, and participant observation as main research techniques. The survey questionnaire was applied to a sample of 71 clients from September $1^{\text {st }}$ to September $30^{\text {th }}, 2011$ in order to diagnose the level of satisfaction with the care provided by the company. Thus, it was possible to assess customer perceptions, pointing out shortcomings in the care provided, while demonstrating to employees the importance in developing a service focused on the needs of customers and not just in achieving goals.
\end{abstract}

Keywords: Quality Attention; Satisfaction; Customer Service.

Revista de Gestão e Secretariado - GeSec, São Paulo, v. 4, n. 2, p 151-176, jul./dez. 2013. 


\section{INTRODUÇÃO}

As empresas de fato precisam estar atentas ao seu cliente, pois ele é o fator determinante do sucesso, cabe a ele adquirir produtos, fazer reclamações sugestões e até mesmo deixar de comprar quando um produto não atende as suas expectativas. Silva e Zambom (2006) demonstram que os clientes bem atendidos e satisfeitos voltam a comprar, demonstram lealdade e ajudam a empresa a prosperar. Para tanto, não existe outra forma de atender bem aos clientes que não seja por meio do conhecimento do seu comportamento.

Nesse sentido, acredita-se ser essencial criar um canal de comunicação comum, por meio do qual os clientes possam reclamar, sugerir ou questionar. Entende-se que as empresas que ouvem seus clientes, identificam mais facilmente as falhas e criam ações corretivas estando à frente em relação aos concorrentes.

Com base nesse pressuposto, um dos principais motivos para desenvolver o estudo nessa área de pesquisa foi a intenção em diagnosticar a maneira como os colaboradores atendiam os clientes e qual a percepção desses em relação ao atendimento recebido. Este estudo justifica-se porque a região de Guarapuava é mantida basicamente pelo comércio e pela agricultura, sendo necessário para as empresas da região, conhecer e entender melhor seus clientes.

Assim, desenvolver uma pesquisa nessa área torna-se viável, pois agrega conhecimento na aprendizagem de experiências práticas no que se refere a empresas locais e a seus clientes. Ou seja, para a empresa, a realização da pesquisa em atendimento auxilia a entender melhor o perfil de seus e permite, assim, identificar suas necessidades. A empresa JM oferece um serviço o qual exige se um diferencial no atendimento, pois o segmento em que a empresa se insere possui produtos e serviços inovadores com tecnologia avançada.

Para tanto, realizar uma pesquisa de satisfação, torna-se um diferencial, pois possibilita a correção dos aspectos negativos que possam ter ocorrido no atendimento, por meio das falhas apontadas pelos clientes. Observa-se a relevância de uma empresa estar atenta aos aspectos que envolvem satisfação de serviços.

Partindo desse pressuposto, esta pesquisa centrou-se em verificar como é prestado o atendimento ao cliente nesta empresa e a partir deste aspecto, mensurar o grau de qualidade dos serviços prestados e satisfação dos clientes, contribuindo com a gestão e o sucesso da mesma. Dessa forma, este estudo visou responder ao seguinte problema de pesquisa: Qual o nível de satisfação dos 
clientes em relação ao atendimento prestado pela empresa JM Alarmes de Guarapuava?

Nesse sentido, os objetivos específicos desenvolvidos na pesquisa foram delimitados da seguinte maneira: a) mensurar a satisfação dos clientes em relação ao atendimento prestado pelos setores administrativo, técnico e operacional da empresa; b) discutir o atendimento da empresa apontado os aspectos positivos e a serem melhorados a partir da perspectiva pelos clientes.

Cabe ressaltar que a pesquisa realizada teve limitações no âmbito da pesquisa bibliográfica, utilizando-se de referências disponíveis e selecionadas pelos pesquisadores, mas sem a pretensão de esgotar todo o universo publicado em atendimento ao cliente no Brasil. Teve limitações ainda, em detalhar todos os modelos referentes ao atendimento propostos como forma de melhoria para a Empresa JM Alarmes.

\section{REFERENCIAL TEÓRICO}

\subsection{QUALIDADE NO ATENDIMENTO}

A compreensão dos clientes a respeito da qualidade depende de suas percepções e ainda se os serviços oferecidos criam determinado grau de satisfação. Para Zeithaml e Bitner (2007, p. 92) “qualidade em serviços, é um componente central das percepções dos clientes”. Segundo Las Casas (2009) a qualidade em serviços está intimamente ligada à satisfação, ou seja, um cliente satisfeito com o prestador de serviços perceberá um serviço como de qualidade. Assim, entende-se que os serviços oferecidos devem ser planejados de forma cuidadosa e, acima de tudo, oferecidos com qualidade. Quando um serviço gera satisfação, ocasionalmente gera o retorno dos clientes e indicações para outros novos clientes.

Ainda de acordo com Las Casas (2009, p. 99), para desenvolver serviços com qualidade, torna-se necessário que "os administradores tenham uma combinação dos procedimentos, como pesquisar, estabelecer uma cultura, desenvolver treinamento, criar um clima organizacional com o marketing interno, comunicar o plano e estabelecer mecanismos de controle". Observa-se então, que todas essas atividades devem seguir o mercado e suas tendências. Por isso a necessidade em desenvolver o programa de qualidade em paralelo com o marketing estratégico de serviços que esteja sintonizado com seu ambiente.

Segundo Townsend (2010), o primeiro requisito para melhorar a qualidade é o compromisso do gestor com o processo e suas metas, passando a ser ativo nesta situação. Por sua vez, um

Revista de Gestão e Secretariado - GeSec, São Paulo, v. 4, n. 2, p 151-176, jul./dez. 2013. 
segundo requisito para uma empresa gerir a qualidade passa a ser o compromisso de todos os envolvidos, sejam funcionários ou gerentes. "O compromisso com a qualidade vai determinar a solidez de uma empresa. Através do compromisso de sempre entregar um produto ou serviço de alto valor proporciona ao cliente a segurança e faz com que sempre volte a comprar desta empresa". (op. cit., 2010, p. 100).

Para Hargreaves, Zuanetti e Lee (2011), quando se fala de serviço de qualidade automaticamente ele é relacionado à plena satisfação do cliente. Os autores consideram que o segredo para atingir tal objetivo está na empresa prestadora de serviços que se concentra profundamente nas necessidades e nos desejos dos clientes, com a criação de serviços que atendam ou excedam as suas expectativas. Esta tem sido a principal maneira de as empresas serem impulsionadas à satisfação do cliente. Para Townsend (2010, p. 108), “o conceito de qualidade e a contribuição possível de cada pessoa tornam se muito mais claro. O cliente não é apenas a última pessoa ou empresa que, de fato, compra e usa o produto ou serviço da empresa, o cliente é qualquer uma a quem um indivíduo fornece qualquer informação, produto ou serviço".

Sendo assim, por meio da citação, percebe-se que a empresa deve se direcionar ao compromisso, pois caso uma das etapas falhem, o produto final ficará comprometido. Desta forma, o comprometimento envolve todos os níveis da empresa. Conforme Denton (2008) "os clientes sentem-se bem quando recebem bom atendimento" (p. 38). Pode-se assim, analisar que a cortesia deve ser recíproca, tanto do cliente para com o funcionário, como do funcionário para o cliente. Ou seja, dificilmente um cliente bem tratado será hostil.

Para Hargreaves, Zuanetti e Lee (2011), outro fator que impulsiona a qualidade no atendimento refere-se a uma boa infraestrutura da empresa, bem como o desempenho direto de cada funcionário aliado ao comprometimento institucional. Os autores citados ressaltam que a qualidade só aparece quando as empresas praticam políticas de valorização e capacitação pessoal. Em outras palavras isto quer dizer que o atendimento é realizado por pessoas, ou seja, funcionários que precisam ser "vistos" pela empresa de uma forma desafiadora, não apenas como máquinas que fazem parte do processo de produção.

Cabe destacar que a qualidade pode ser utilizada em diversas situações, porém na área dos negócios se torna uma importante aliada, que contribui para o crescimento e solidificação da organização, com a elevação do seu nível e tornando-a realmente competitiva. Neste sentido, a terminologia da palavra em si, pode ter diferentes significados. 
Segundo Gianesi e Corrêa (2008), a noção de qualidade é muito ampla e para isto se torna relevante e necessário conceituar qualidade de serviços baseada na opinião dos consumidores. Para tanto, este conceito deve ser claro para os gestores, de modo que estes possam tomar decisões que visem à melhoria da qualidade esperada pelos consumidores. Neste ínterim, os autores mencionados afirmam que "qualidade envolve tudo aquilo que diz respeito ao produto" (op. cit., 2008, p. 54).

Dessa forma, pode-se dizer que quem decide se um produto/serviço é de qualidade é o cliente. Isso faz com que as empresas busquem identificar o que os clientes consideram como atributos adequados dos produtos e serviços que consomem. Assim, também é necessário comunicar aos colaboradores quais são esses atributos de forma que seja possível atingir a satisfação do cliente.

Segundo Las Casas (2009, p. 95) para "satisfazer o cliente é preciso que o serviço ou produto seja de qualidade". Então, se observa que apresentar qualidade aos clientes tornou-se uma obrigação por parte das empresas, pois a concorrência a cada dia se torna mais acirrada e todas são dependentes dos consumidores que são sua principal fonte de renda. $\mathrm{O}$ mesmo autor cita ainda que há certa negligência por parte das empresas no Brasil, o que cria grande dificuldade na negociação com tais empresas. Os clientes em grande parte percebem a qualidade ainda no contato pessoal com os funcionários de uma empresa.

Cobra (2009) afirma que o objetivo de todos na organização deve ser de alguma maneira procurar "não apenas satisfazer as necessidades do cliente, mas também às suas mais exigentes expectativas" (p. 34). Dessa maneira, parte-se do pressuposto que para que esse processo ocorra deve-se compreender o comportamento do cliente e o que ele realmente deseja ou espera da empresa. Dito de outra forma, compreender as expectativas do cliente pode facilitar a interação e proporcionar mais agilidade ao atendimento e certamente satisfação, não apenas pela compra em si, mas pelo prazer de ser bem atendido.

Considera-se que entender o cliente seja primordial para alcançar sucesso em todos os segmentos. Ou seja, atender bem significa reconhecer a demanda que os consumidores têm procurado nos produtos. Dessa forma, concorda-se que um bom relacionamento com o cliente favorece a vantagem competitiva.

Em contraponto, caso a percepção do cliente seja a insatisfação quanto à qualidade oferecida pelo fornecedor, este deve estar preparado para realizar alguma ação no intuito de corrigir a falha encontrada pelo cliente, sendo que tal ação deve ser relacionada com a reação dele - o cliente. $\mathrm{O}$ impacto negativo da insatisfação de um cliente, resulta em depoimentos capazes de destruir a propaganda indireta da empresa.

Revista de Gestão e Secretariado - GeSec, São Paulo, v. 4, n. 2, p 151-176, jul./dez. 2013. 


\title{
2.2 SATISFAÇÃO DOS CLIENTES
}

Para Mirshawka (1993) a satisfação do cliente pode ser identificada como um estado no qual as necessidades, desejos e expectativas são atendidos ou excedidos, que resultam em um retorno para comprar ou adquirir um produto ou serviço.

De acordo com Levy e Weitz (2000) todo o cliente tem um conjunto único de necessidades, o que faz a diferença na escolha de sua compra é seu estado emocional no momento aliado a soma de benefícios agregados ao produto ou serviço escolhido. De modo que é imprescindível analisar e compreender o cliente de forma única e particular, empresas preparadas para tal saem na frente em relação aos seus concorrentes.

Ainda para Levy e Weitz (2000) a fidelidade do cliente não significa que os clientes gostam de fazer compras em determinada loja, mas a fidelidade é estar comprometidos de modo que sempre continuarão a comprar na mesma loja. E este aspecto também pode ser verificado na prestação de serviços A satisfação para Kotler e Armstrong (2007) é quando os clientes formam expectativas em relação ao valor que as várias ofertas proporcionarão, ou seja, fazem suas escolhas com base em suas expectativas. Se essas forem supridas certamente comprarão novamente, caso contrário, sairão insatisfeitos, mudarão para a concorrente e ainda haverá uma depreciação dos produtos e serviços das outras empresas que não conseguirão superar suas expectativas.

Para Las Casas (2009, p. 83)

\begin{abstract}
Um cliente forma expectativas de acordo com as promessas feitas pelos vendedores de serviços, pelas experiências passadas com a empresa ou concorrentes ou até mesmo com o comentário de outras pessoas. Essas expectativas são essenciais para a satisfação. Se o resultado de uma prestação de serviços iguala a expectativa, o cliente fica satisfeito. No entanto, se o resultado da prestação de serviços ficar aquém das expectativas, os clientes ficarão insatisfeitos. O equilíbrio é proveniente de uma boa coordenação do nível da prestação de serviços e das promessas feita aos clientes.
\end{abstract}

Conforme apresenta a citação, observa-se ser o cliente a pessoa que garante a permanência da empresa no mercado, sendo necessário, dessa maneira, garantir sua satisfação. Entretanto, a satisfação dos clientes não é suficiente para garantir a competitividade, pois eles podem estar 
satisfeitos com os produtos da empresa e mesmo assim migrar para a concorrência. A empresa deve focar na qualidade e no valor percebido pelo mercado versus concorrentes. Logo é feita a comparação dos produtos da empresa com as da concorrência, pois apesar de classificar um produto como bom, o cliente poderá deixar de comprá-lo se perceber que existem outros que são melhores. (Di Serio \& Vasconcellos, 2009).

Para Johnston e Clark (2007, p. 17) o propósito em entender os clientes "é assegurar que o serviço pode ser preparado e entregue para atender as expectativas. Se a operação atende as expectativas, ou, de fato, as excedem, os clientes ficam satisfeitos com o serviço". Nesse sentido, analisa-se que se os clientes estiverem satisfeitos, é provável que voltem a comprar novamente o produto e/ou serviços e ainda recomendá-los a outros.

Em complemento, os mesmos autores afirmam que se a percepção, a experiência e os resultados do serviço atendem às expectativas do cliente, ele deve ficar satisfeito. Se sua percepção do serviço exceder às expectativas, ele ficará mais do que satisfeito, ou até encantado. (op. cit., p. 23)

Concordando, Hooley e Saunders (2006), consideram em seus estudos que os clientes esperam certo grau de benefício ao comprar ou usar um produto/serviço. A empresa que conseguir superar as expectativas do cliente, proporcionando-lhe algo mais próximo de seu desejo, estará diante da oportunidade de ir além da satisfação do cliente, criando assim o "encantamento do cliente" (Hooley \& Saunders, 2006, p. 29).

Dessa forma, observa-se que para os autores mencionados, toda e qualquer ação realizada para promover a satisfação do cliente é válida, pois quando as empresas superam as expectativas dele, há maior probabilidade que este volte a comprar e ainda promova a fidelização. Ou seja, acredita-se que as empresas precisam desenvolver estratégias, a fim de mobilizar a equipe para atender bem o cliente e garantir a satisfação e por meio dela obter os recursos para manter-se atuante no mercado.

\subsection{PRESTAÇÃO DE SERVIÇOS}

O serviço traz ao consumidor sensações e experiências pelo fato de não se tratar de algo material, conforme abordam Zeithaml e Bitner (2007) os serviços são atividades econômicas, cujo produto é geralmente consumido no momento em que é produzido e proporciona valor agregado, são inclusos os serviços de conveniências, saúde, conforto e oportunidades que são criados de acordo com a demanda.

Revista de Gestão e Secretariado - GeSec, São Paulo, v. 4, n. 2, p 151-176, jul./dez. 2013. 
Para Kotler (1998), os serviços podem ser enquadrados em cinco categorias: a) bem tangível: a oferta consiste apenas em um bem tangível; b) bem tangível acompanhado de serviços: a oferta acompanha um ou mais serviços; c) híbrido: a oferta consiste em partes iguais de bens e serviços; d) serviço principal acompanhado de bens e serviços secundários: a oferta consiste em um serviço principal junto com serviços adicionais; e d) serviço: a oferta consiste principalmente em um serviço. Esses são alguns compostos de serviços que permitem a distinção entre os serviços prestados.

O mesmo autor cita, ainda, que os serviços possuem características próprias as quais afetam os desenhos dos programas de marketing, sendo elas definidas como intangibilidade, inseparabilidade, variabilidade e perecibilidade, as quais serão abordadas em seguida.

A intangibilidade é algo que deve ter a preocupação por parte das empresas em relação ao atendimento que oferecem aos seus clientes. Diferente dos produtos que são bens materiais "tangíveis” os serviços são "intangíveis", ou seja, eles desaparecem após a sua conclusão, restando apenas o sentimento ou percepção do cliente.

Segundo Urdan e Urdan (2006, p. 110) "a intangibilidade combinada com a inseparabilidade e a variabilidade aumentam o risco percebido pelo cliente na escolha de determinado serviço". Diante da inexistência de alguma experiência vivenciada pelo cliente em relação a algum serviço, torna-se difícil imaginar o que pode ser obtido após contratá-lo ou vivenciá-lo, tornando mais difícil ainda a escolha de onde e como vai adquiri-lo.

Os mesmos autores mostram que alguns profissionais da área de marketing têm adotado estratégias para enfrentar dificuldades relacionadas à intangibilidade, como a) tangibilizar o intangível com comunicação; b) acentuar e valorizar os elementos tangíveis e c) oferecer garantias de serviços.

$\mathrm{O}$ ato de tangibilizar o intangível por meio da comunicação se faz quando o prestador, de alguma maneira, procura sanar dúvidas quanto ao serviço oferecido, reduzindo significativamente os empecilhos encontrados pelo cliente. Uma forma de fazer isso é levar ao conhecimento dos clientes experiências vividas, provas reais das vantagens oferecidas a eles, o que de certa maneira vai servir de estímulo para o cliente contratar o serviço (Urdan \& Urdan, 2006).

A valorização dos "objetos" tangíveis que os serviços possuem como funcionários, instalações físicas e equipamentos materiais podem ser utilizados para, de certa maneira, prender a atenção dos clientes, sendo que com isso pode ser possível transmitir ideias ou sentimentos, os 
mesmos autores indicam que os elementos físicos funcionam como pistas para o cliente sobre a capacidade e o perfil do prestador do serviço. (Kotler, 1998)

Já a inseparabilidade é abordada da seguinte maneira: no mercado existe uma grande variedade de serviços que cabem as características desta, os quais fazem parte do nosso dia a dia, porém poucos conhecem tal definição. Segundo Urdan e Urdan (2006, p. 102) "inseparabilidade significa que serviços são produzidos ao mesmo tempo em que são consumidos". Nessa categoria de prestação de serviços o consumidor tem bastante influência, pelo fato de ser participante da produção de tal serviço - o que, consequentemente, interfere no resultado final, pois o consumidor está em contato com o prestador do serviço ficando um exposto às variáveis comportamentais do outro. Os mesmos autores afirmam ainda que a inseparabilidade gera interações dos clientes com os prestadores, recursos técnicos e demais clientes presentes.

Os serviços que assumem tal característica exigem atenção e preparo por parte do prestador pelo fato de este estar em contato - muitas vezes direto - com o consumidor. Nos casos em que os serviços são produzidos sem a presença do cliente as chances de corrigir alguma falha que venha a ocorrer durante o processo são maiores, diminuindo os riscos de a comercialização ser afetada, pois o cliente não terá o conhecimento de que algum a falha aconteceu durante o processo. No caso de o cliente estar presente, até o momento da correção de tal falha, gera-se um momento de espera por parte do consumidor - o que afetará, consequentemente a percepção da qualidade pelo serviço. Diante disso, todas as áreas funcionais devem interagir em harmonia - qualquer atitude de uma área pode afetar as demais. (Urdan \& Urdan, 2006, p. 102)

A variabilidade influencia todos os ramos de atividades das empresas atuantes no mercado, as percepções da qualidade em todos os requisitos exigidos por parte do cliente. Para Urdan e Urdan (2006, p. 103) "um dos potenciais geradores da variabilidade é a grande e frequente interação humana, assim como a inseparabilidade".

Assim como existem diversas maneiras de o fornecedor proceder a um atendimento no intuito de satisfazer algum desejo, existem diversas formas de o cliente avaliar o desempenho do fornecedor em determinada tarefa. Urdan e Urdan (2006) trazem a definição de variabilidade como um serviço pode ser variável de um cliente para outro, de funcionário para funcionário, assim como de empresa para empresa. Ou seja, o que pode ser bom para determinada pessoa pode não ser para outra, assim como determinada empresa ache coerente realizar determinada tarefa da maneira A, e outra empresa da maneira B.

Diferente dos bens materiais que podem ser estocados até o momento do seu consumo, os serviços devem ser produzidos de acordo com sua demanda. Em virtude de os serviços envolverem

Revista de Gestão e Secretariado - GeSec, São Paulo, v. 4, n. 2, p 151-176, jul./dez. 2013. 
custos ao prestador cabe a ele planejar e prever os pontos altos da demanda para que não ocorram problemas com os clientes. Os mesmos autores citam algumas atitudes que podem amenizar os impactos causados pela perecibilidade como a utilização de empresas terceirizadas que possam auxiliar nos picos da demanda ou oferecer treinamentos aos funcionários, deixando-os aptos a realizar diferentes tarefas, se necessário.

\section{METODOLOGIA DA PESQUISA}

Esta pesquisa caracteriza-se como um estudo de caso de cunho exploratório e de campo, com abordagem qualitativa e quantitativa. As pesquisas exploratórias proporcionam maior familiaridade com o problema levantado, deixando-o mais claro a ponto de tornar-se explícito e auxiliar na construção de hipótese (Gil, 2006).

Neste sentido, a pesquisa classifica-se como qualitativa porque fez uso de análises detalhadas sobre os dados colhidos inclusive investigando hábitos e atitudes no ambiente organizacional. Godoy (1995, p. 62) apresentou, em seus estudos sobre pesquisa qualitativa, um conjunto de características essenciais capazes de identificar esta forma de pesquisa: "1. O ambiente natural como fonte direta de dados e o pesquisador como instrumento fundamental; 2. o caráter descritivo; 3. o significado que as pessoas dão às coisas e a sua vida como preocupação do investigador; 4. enfoque indutivo".

A pesquisa também se classifica com quantitativa, porque faz uso de dados quantitativos. Lima (2008, p. 43) afirma que a:

Pesquisa quantitativa é orientada para o raciocínio hipotético dedutivo, o qual permite a formulação de hipóteses do objeto, identifica as consequências e delineia o universo da pesquisa. Também define a amostra que será estudada, a coleta de dados prioriza as informações que possam ser quantificadas e o foco central da pesquisa reside no fato de testar a hipótese a fim de validá-la ou não.

Sendo assim, utilizaram-se como principais técnicas de coleta de dados a pesquisa bibliográfica, o questionário em formato likert, a pesquisa documental, a observação participante e o diário de campo. Para tanto, a construção da primeira etapa da pesquisa - 2/2/2011 a 2/5/2011 objetivou pesquisar sobre satisfação e qualidade na prestação de serviços. Nesta etapa, optou-se em 
utilizar como técnica central a pesquisa bibliográfica em autores que tratam especificamente desta temática.

Por sua vez, a pesquisa em campo (segunda etapa) foi realizada no período de 2/4/2011 a 2/10/2011, que totalizaram cinco meses, em formato de 20 horas semanais. Assim, ao todo, a pesquisa em campo abrangeu 100 horas que foram registradas em diário de campo específico.

Nesta etapa utilizou-se como técnica central de pesquisa o questionário em formato likert (Apêndice 1) e que foi aplicado em uma amostra composta por 71 clientes, distribuídos via correio eletrônico para aproximadamente 200 clientes que estavam cadastrados na base de dados da empresa. Este questionário foi aplicado no período de 1 a 30 de setembro de 2011, que visou descobrir o nível de satisfação em relação ao atendimento prestado pela empresa.

Cabe destacar, que para aplicação dos questionários, realizou-se um plano de amostragem, de obter um número de respostas confiáveis. Nesse sentido, as amostras corresponderam a parcelas do todo, as quais foram extraídas e analisadas por envolver populações grandes, ou seja, populações finitas, permitindo a contagem de seus elementos (Bruni, 2010).

Em complemento, nesta etapa, utilizou-se ainda, a pesquisa documental referente aos relatórios sobre atendimento e prestação de serviços dispostos nos arquivos da empresa. Também foram utilizadas as técnicas de observação participante e diário de pesquisa para registrar os atendimentos realizados.

Na terceira etapa da pesquisa - 3/10/2011 a 3/11/2011 - após a coleta, os dados dispostos nos questionários foram analisados com o emprego de técnicas estatísticas descritivas e o apoio do software SPSS. Concomitantemente, os resultados estatísticos foram triangulados com as descrições realizadas na observação participante e registradas no diário de pesquisa. A técnica estatística foi relacionada com a tabulação das respostas obtidas nos questionários sendo, então demonstradas graficamente por meio de análise descritiva a qualitativa em formato de quadros explicativos.

\section{RESULTADOS E DISCUSSÕES}

De acordo com o diagnóstico organizacional, a JM Alarmes tem como atividade econômica a venda de produtos e a prestação de serviços de monitoramento, vigilância e assistência técnica.

A empresa presta serviços de monitoramento dos estabelecimentos comerciais e residências onde são instalados equipamentos eletrônicos de segurança, que permanecem conectados 24 horas com uma base alocada no interior da empresa. Em caso de alguma ocorrência registrada, dispõe de

Revista de Gestão e Secretariado - GeSec, São Paulo, v. 4, n. 2, p 151-176, jul./dez. 2013. 
uma equipe que se desloca até o local, visando oferecer maior segurança aos clientes e suporte em eventuais emergências.

A empresa iniciou suas atividades no ano de 2005 na cidade de Guarapuava-PR e em 2011, ela registrava em sua base de dados cerca de 1600 clientes.

\subsection{PESQUISA DA SATISFAÇÃO: O QUE DIZEM OS CLIENTES?}

Apresentam-se, a seguir, os resultados obtidos por meio da pesquisa de satisfação realizada na empresa JM Alarmes. Com as informações coletadas foi possível identificar a opinião dos clientes no que diz respeito à qualidade dos serviços prestados pela organização. Abaixo, o perfil dos respondentes:

\subsubsection{PERFIL DOS RESPONDENTES}

A amostra do estudo foi composta de 71 respondentes, sendo 31 deles clientes comerciais, 23 residenciais e 17 que não responderam a essa questão. A maior parte dos respondentes (53,5\%) foi constituída por clientes do sexo masculino, enquanto que $40,8 \%$ são do sexo feminino e $5,6 \%$ não foram identificados.

Em relação à faixa etária, observa-se que a maioria dos clientes apresenta idade entre 29 e $39 \operatorname{anos}(43,7 \%)$, entre 18 a 28 anos (22,5\%), seguido por $16,9 \%$ com idade entre 40 a 50 anos, $11,3 \%$ com idade entre 51 a 61 anos, 1,4\% acima de 61 anos e 4,2\% não quiseram se identificar. Tal classificação pode ser observada no Quadro 1 a seguir:

\begin{tabular}{|l|c|c|}
\hline & PERCENTUAL & PERCENTUAL ACUMULADO \\
\hline De 18 a 28 anos & 22,50 & 22,50 \\
\hline De 29 a 39 anos & 43,70 & 66,20 \\
\hline De 40 a 50 anos & 16,90 & 83,10 \\
\hline De 51 a 61 anos & 11,30 & 94,40 \\
\hline
\end{tabular}

Revista de Gestão e Secretariado - GeSec, São Paulo, v. 4, n. 2, p 151-176, jul./dez. 2013. 


\begin{tabular}{|l|c|c|}
\hline Acima de 61 anos & 1,40 & 95,80 \\
\hline Em branco & 4,20 & 100,00 \\
\hline Total & 100,00 & \\
\hline
\end{tabular}

Quadro 1 - Faixa etária dos respondentes.

Fonte: Dados do Questionário (2011).

Conforme o Quadro 1, constata-se que a maioria dos clientes estão na faixa de idade entre 29 a 39 anos, o que pode ser explicado devido ao fato de serem pessoas que estão na fase de construir famílias, casar, adquirir bens e imóveis, estabelecer empresas - e isso remete ao fato de que estes respondentes busquem adquirir serviços de segurança para manter seu patrimônio.

No que se refere à renda familiar, 54,9\% dos clientes respondentes possuem renda de 1 a 4 salários mínimos, 1,4\% dos respondentes recebem em média de 5 a 9 salários mínimos, cerca de 18,3\% possuem renda em média 10 a 14 salários mínimos, $15,5 \%$ dos respondentes ganham de 15 a 19 salários mínimos, 5,6\% ganham acima de 20 salários mínimos e 4,2\% não quiseram responder a essa questão. Tal aspecto é expresso no Quadro 2.

\begin{tabular}{|l|c|c|}
\hline & PERCENTUAL & PERCENTUAL ACUMULADO \\
\hline 1 a 4 salários mínimos & 54,90 & 54,90 \\
\hline 5 a 9 salários mínimos & 1,40 & 56,30 \\
\hline 10 a 14 salários mínimos & 18,30 & 74,60 \\
\hline 15 a 19 salários mínimos & 15,50 & 90,10 \\
\hline Acima de 20 salários mínimos & 5,60 & 95,80 \\
\hline Em branco & 4,20 & 100,00 \\
\hline Total & 100,00 & \\
\hline
\end{tabular}

Quadro 2 - Renda familiar dos respondentes.

Fonte: Dados do Questionário (2011).

Revista de Gestão e Secretariado - GeSec, São Paulo, v. 4, n. 2, p 151-176, jul./dez. 2013. 
De acordo com dados da ABEP (Associação Brasileira das Empresas de Pesquisa) para o ano de 2008 aproximadamente $68 \%$ da população inseria-se nas classes sociais de C a D - o que corresponde média de 1 a 4 salários mínimos. Tais dados podem explicar o fato da empresa ter mais clientes com essa renda familiar. Em complemento, o Quadro 3 demonstra há quanto tempo os clientes utilizam os serviços da JM Alarmes.

\begin{tabular}{|l|c|c|}
\hline & PERCENTUAL & PERCENTUAL ACUMULADO \\
\hline Menos de 6 meses & 5,60 & 5,60 \\
\hline Entre 6 meses e 1 ano & 33,80 & 39,40 \\
\hline Entre 2 a 5 anos & 40,80 & 80,20 \\
\hline Mais que 6 anos & 14,10 & 94,30 \\
\hline Em branco & 5,60 & 100,00 \\
\hline Total & 100,00 & \\
\hline
\end{tabular}

Quadro 3 - Tempo de utilização dos serviços pelos respondentes.

Fonte: Dados do Questionário (2011).

Em relação ao tempo que os clientes utilizam os serviços da JM Alarmes, verifica-se conforme Quadro 3, que 5,60\% dos respondentes utilizam o sistema há menos de seis meses e $33,8 \%$ estão utilizando os serviços entre seis meses e um ano. Nesse sentido, observa-se que uma boa parte são clientes novos. Por outro lado, observa-se que 40,8\% são clientes entre dois e cinco anos e cerca de $14,1 \%$ utilizam os serviços há mais de seis anos, ou seja, são clientes há bastante tempo, o que evidencia a fidelidade dos clientes para com a empresa.

\subsubsection{ATITUDE DO CLIENTE EM RELAÇÃO À EMPRESA E OCORRÊNCIA DE} PROBLEMAS

Revista de Gestão e Secretariado - GeSec, São Paulo, v. 4, n. 2, p 151-176, jul./dez. 2013. 
Durante a aplicação da pesquisa foi abordado se os clientes recomendariam os serviços prestados pela JM e cerca de 70,4\% do respondentes afirmaram que já recomendaram os serviços. Por outro lado, 23,9\% dos respondentes não recomendam os serviços e 5,6\% não quiseram responder a essa questão. Ainda na pesquisa os clientes foram indagados se tiveram problemas com os serviços da empresa e com quais setores.

Do total de respondentes, $22,5 \%$ disseram que tiveram problemas com o sistema de alarme. Esse número foi consideravelmente expressivo em relação ao número de clientes e considerando que a empresa têm vários concorrentes, o que identificou uma possível ameaça para a empresa.

Em torno de 8,5\% afirmaram ter tido problemas com os atendentes de alarme e técnicos; 7,0\% afirmaram ter tido problemas com a telefonista; 4,2\% afirmaram ter tido problemas com o financeiro; 4,2\% afirmaram ter tido problemas com os vendedores; 47,9\% afirmaram que não tiveram problemas com os serviços prestados e 5,6\% não quiseram responder a essa questão. Esses dados são apresentados no Quadro 4.

\begin{tabular}{|l|c|c|}
\hline & PERCENTUAL & PERCENTUAL ACUMULADO \\
\hline Sim, com os atendentes e técnicos & 8,50 & 8,50 \\
\hline Sim, com os vendedores & 4,20 & 12,70 \\
\hline Sim, com o financeiro & 4,20 & 16,90 \\
\hline Sim, com o sistema de alarme & 22,50 & 39,40 \\
\hline Sim, com a telefonista & 7,00 & 46,40 \\
\hline Não & 47,90 & 94,30 \\
\hline Em branco & 5,60 & 100,00 \\
\hline Total & 100,00 & \\
\hline
\end{tabular}

Quadro 4 - Problemas com serviços da JM Alarmes.

Fonte: Dados do Questionário (2011). 
O Quadro 4 aponta que a maior parte dos problemas ocorreu com o sistema de alarme, evidenciando problemas técnicos com o sistema de monitoramento deste. Tais problemas podem ser explicados por ter havido fusões com outras empresas, das quais migraram clientes juntamente com equipamentos usados.

Em seguida, verifica-se que $8,5 \%$ já tiveram problemas com os atendentes de alarme e os técnicos; percebe-se um descontentamento por parte dos respondentes o que evidencia problemas que ocorreram na prestação dos serviços e no atendimento ao cliente. Tal fator merece especial monitoramento por parte da empresa.

Os clientes foram questionados ainda, se quando ocorrem problemas, estes são de fato resolvidos e 50,7\% afirmaram que sim; ao fazerem a solicitação são atendidos. Por outro lado, 40,8\% dos respondentes afirmaram que os problemas não são resolvidos, o que é considerado um número grande em relação aos clientes da empresa. Esta afirmação pode ser explicada em virtude de não haver o assessoramento correto quanto às manutenções e reparos ou ainda pode demonstrar o uso incorreto do sistema de alarme pelo usuário.

\subsubsection{AVALIAÇÃO DA SATISFAÇÃO QUANTO AOS SERVIÇOS PRESTADOS}

A percepção dos clientes quanto aos serviços prestados pela empresa foi obtida a partir da aplicação do instrumento de pesquisa em que se detalhou o atendimento ao cliente nos setores de recepção, vendas, na equipe técnica, na central de monitoramento e no administrativo/financeiro.

Para as análises propostas a seguir utilizou-se a seguinte fórmula: a soma de porcentagens de "Discordo totalmente" + "Discordo" + "Indeciso" remetem a atitudes negativas. A soma de "Concordo" + "Concordo totalmente" remetem a atitudes positivas.

\subsubsection{Recepção}

\begin{tabular}{|l|c|c|c|c|c|c|c|}
\hline & $\begin{array}{c}\text { DISCORDO } \\
\text { TOTALMENTE }\end{array}$ & DISCORDO & INDECISO & CONCORDO & $\begin{array}{c}\text { CONCORDO } \\
\text { TOTALMENTE }\end{array}$ & $\begin{array}{c}\text { NÃO SEI, } \\
\text { NUNCA } \\
\text { UTILIZI }\end{array}$ & $\begin{array}{c}\text { TOTAL } \\
\text { \% }\end{array}$ \\
\hline $\begin{array}{l}\text { O atendimento } \\
\text { telefônico é bom }\end{array}$ & 0,00 & 1,40 & 5,60 & 66,20 & 25,40 & 1,40 & 71 \\
\hline
\end{tabular}




\begin{tabular}{|c|c|c|c|c|c|c|c|c|}
\hline $\begin{array}{l}\mathrm{O} \text { atendimento na } \\
\text { recepção é bom }\end{array}$ & 0,00 & 0,00 & 1,40 & 28,60 & 15,70 & 54,30 & 70 & 100,00 \\
\hline $\begin{array}{l}\text { conforto na } \\
\text { recepção é bom }\end{array}$ & 0,00 & 1,40 & 1,40 & 27,10 & 4,30 & 65,70 & 70 & 99,90 \\
\hline $\begin{array}{lr}\quad \text { número } & \text { de } \\
\text { atendentes } & \text { na } \\
\text { recepção } & \text { é } \\
\text { suficiente } & \end{array}$ & 0,00 & 0,00 & 1,40 & 31,40 & 7,10 & 60,00 & 70 & 99,90 \\
\hline O ambiente é limpo & 0,00 & 0,00 & 1,40 & 31,40 & 10,00 & 57,10 & 70 & 99,90 \\
\hline $\begin{array}{l}\text { A localização do } \\
\text { prédio é de fácil } \\
\text { acesso }\end{array}$ & 0,00 & 0,00 & 4,20 & 56,30 & 28,20 & 11,30 & 71 & 100,00 \\
\hline $\begin{array}{lr}\text { Sou rapidamente } \\
\text { atendido r } \\
\text { chego ruando } \\
\text { estabelecimento }\end{array}$ & 0,00 & 0,00 & 2,90 & 31,90 & 8,70 & 56,50 & 69 & 100,00 \\
\hline $\begin{array}{lr}\text { O horário } & \text { de } \\
\text { atendimento } & \text { é } \\
\text { adequado } & \end{array}$ & 0,00 & 1,40 & 2,90 & 47,10 & 20,00 & 28,60 & 70 & 100,00 \\
\hline $\begin{array}{l}\text { Recebo uma } \\
\text { atenção } \\
\text { individualizada }\end{array}$ & 1,50 & 4,40 & 8,80 & 42,60 & 13,20 & 29,40 & 68 & 99,90 \\
\hline $\begin{array}{l}\text { As instalações } \\
\text { físicas são atraentes }\end{array}$ & 0,00 & 1,40 & 4,20 & 45,10 & 14,10 & 35,20 & 71 & 100,00 \\
\hline $\begin{array}{llr}\text { Quando } & \text { ligo } & \text { na } \\
\text { empresa } & \text { sou } & \text { bem } \\
\text { atendido } & \text { e } & \text { minhas } \\
\text { dúvidas } & & \text { são } \\
\text { supridas } & & \end{array}$ & 1,40 & 5,70 & 7,10 & 52,90 & 32,90 & 0,00 & 70 & 100,00 \\
\hline
\end{tabular}

Quadro 5 - Avaliação dos serviços prestados pela recepção, por sentenças.

Fonte: Dados do Questionário (2011).

De acordo com o Quadro 5, observa-se 14,7\% dos respondentes afirmaram que não receberam uma atenção individualizada. Por sua vez, 14,2\% dos respondentes alegaram que quando telefonaram para a empresa não foram bem atendidos e suas dúvidas não foram supridas. Constatou-se que os respondentes demonstraram descontentamento com o atendimento telefônico. (Diário de Campo, 2011).

No que se refere ao posicionamento dos clientes quanto às instalações físicas oferecidas pela empresa, percebeu-se que $84,50 \%$ dos clientes afirmara que a localização da empresa é de fácil acesso, $65,7 \%$ deles nunca estiveram presentes nas instalações físicas da empresa.

\subsubsection{Vendas}

Revista de Gestão e Secretariado - GeSec, São Paulo, v. 4, n. 2, p 151-176, jul./dez. 2013. 


\begin{tabular}{|l|c|c|c|c|c|c|c|c|}
\hline & $\begin{array}{c}\text { DISCORDO } \\
\text { TOTALMENTE }\end{array}$ & DISCORDO & INDECISO & CONCORDO & $\begin{array}{c}\text { CONCORDO } \\
\text { TOTALMENTE }\end{array}$ & $\begin{array}{c}\text { NÃO SEI, } \\
\text { NUNCA }\end{array}$ & TOTAL & \% \\
\hline $\begin{array}{l}\text { UTILI } \\
\text { O atendimento dos } \\
\text { vendedores é bom }\end{array}$ & 0,00 & 2,90 & 14,30 & 50,00 & 27,10 & 5,70 & 70 & 100,0 \\
\hline $\begin{array}{l}\text { Os vendedores } \\
\text { possuem } \\
\text { conhecimento dos } \\
\text { produtos que a } \\
\text { empresa fornece }\end{array}$ & 1,40 & 1,40 & 14,30 & 51,40 & 25,70 & 5,70 & 70 & 99,90 \\
\hline $\begin{array}{l}\text { Os vendedores } \\
\text { oferecem produtos } \\
\text { de acordo com as } \\
\text { minhas reais } \\
\text { necessidades }\end{array}$ & 1,40 & 5,80 & 5,80 & 58,00 & 23,20 & 5,80 & 69 & 100,0 \\
\hline $\begin{array}{l}\text { Os vendedores são } \\
\text { prestativos } \\
\text { cordiais }\end{array}$ & 0,00 & 2,90 & 8,60 & 57,10 & 27,10 & 4,30 & 70 & 100,0 \\
\hline $\begin{array}{l}\text { Os vendedores são } \\
\text { devidamente } \\
\text { uniformizados e } \\
\text { identificados }\end{array}$ & 0,00 & 1,40 & 1,40 & 57,10 & 34,30 & 5,70 & 70 & 99,90 \\
\hline $\begin{array}{l}\text { Os vendedores } \\
\text { cumprem com os } \\
\text { prazos dentrega } \\
\text { dos serviços }\end{array}$ & 1,40 & 10,10 & 13,00 & 42,00 & 29,00 & 4,30 & 69 & 99,80 \\
\hline $\begin{array}{l}\text { O treinamento do } \\
\text { sistema oferecido } \\
\text { pelos vendedores é } \\
\text { bom }\end{array}$ & 0,00 & 5,70 & 12,90 & 54,30 & 21,40 & 5,70 & 70 & 100,0 \\
\hline
\end{tabular}

Quadro 6 - Avaliação dos serviços prestados pela equipe de vendas, por sentenças. Fonte: Dados do Questionário (2011).

Conforme o Quadro 6, verifica-se que 24,50\% dos respondentes afirmaram que os vendedores não cumpriram os prazos de entrega dos serviços; $21,40 \%$ afirmaram que tiveram dúvidas após o treinamento. No que diz respeito ao serviço prestado pela equipe de vendas percebeu-se um considerável descontentamento dos clientes quanto à postura e responsabilidade dos vendedores com os prazos de entrega dos serviços, bem como com a falta de esclarecimentos sobre o sistema e produtos (Diário de Campo, 2011).

Em complemento, 18,6\% dos respondentes afirmaram que o atendimento dos vendedores não foi bom. Pode-se dizer nesse caso que é um índice elevado por tratar-se de uma empresa que preza pela qualidade no atendimento ao cliente - sendo assim deveria apresentar números

Revista de Gestão e Secretariado - GeSec, São Paulo, v. 4, n. 2, p 151-176, jul./dez. 2013. 
menores de reclamações. Em contrapartida, 91,40\% dos respondentes disseram que os vendedores são devidamente uniformizados e identificados; $86,90 \%$ afirmaram que os produtos são de qualidade e $84,90 \%$ disseram que os vendedores são prestativos e cordiais.

\subsubsection{Central de Monitoramento}

\begin{tabular}{|c|c|c|c|c|c|c|c|c|}
\hline & $\begin{array}{c}\text { DISCORDO } \\
\text { TOTALMENTE }\end{array}$ & DISCORDO & INDECISO & CONCORDO & $\begin{array}{c}\text { CONCORDO } \\
\text { TOTALMENTE }\end{array}$ & $\begin{array}{c}\text { NÃO SEI, } \\
\text { NUNCA } \\
\text { UTILIZEI }\end{array}$ & TOTAL & $\%$ \\
\hline & $\%$ & $\%$ & $\%$ & $\%$ & $\%$ & $\%$ & & \\
\hline $\begin{array}{l}\text { O atendimento das } \\
\text { operadoras é bom }\end{array}$ & 0,00 & 5,60 & 5,60 & 59,20 & 28,20 & 1,40 & 71 & 100,00 \\
\hline $\begin{array}{l}\text { Minhas dúvidas são } \\
\text { sempre supridas }\end{array}$ & 0,00 & 4,20 & 11,30 & 53,50 & 28,20 & 2,80 & 71 & 100,00 \\
\hline $\begin{array}{|lr|}\text { Quando } & \text { solicito } \\
\text { algum } & \text { auxílio } \\
\text { sempre recebo }\end{array}$ & 0,00 & 7,10 & 4,30 & 57,10 & 30,00 & 1,40 & 70 & 99,90 \\
\hline $\begin{array}{l}\text { As operadoras } \\
\text { entendem minhas } \\
\text { reais necessidades }\end{array}$ & 1,40 & 4,20 & 7,00 & 54,90 & 31,00 & 1,40 & 71 & 99,90 \\
\hline $\begin{array}{ll}\text { Estou } & \text { satisfeito } \\
\text { com os } & \text { serviços } \\
\text { prestados } & \end{array}$ & 0,00 & 5,60 & 7,00 & 57,70 & 28,20 & 1,40 & 71 & 99,90 \\
\hline $\begin{array}{lr}\text { As operadoras } & \text { são } \\
\text { cordiais } & \mathrm{e} \\
\text { atenciosas } & \end{array}$ & 0,00 & 0,00 & 2,80 & 54,90 & 39,40 & 2,80 & 71 & 99,90 \\
\hline $\begin{array}{l}\text { Sou atendido com } \\
\text { agilidade }\end{array}$ & 0,00 & 11,40 & 2,90 & 50,00 & 32,90 & 2,90 & 70 & 100,00 \\
\hline \begin{tabular}{|l} 
Os atendentes de \\
alarme prestam \\
atendimento com \\
qualidade
\end{tabular} & 0,00 & 4,20 & 5,60 & 60,60 & 28,20 & 1,40 & 71 & 100,00 \\
\hline $\begin{array}{l}\text { Quando solicito a } \\
\text { presença de um } \\
\text { atendente em minha } \\
\text { residência/comércio } \\
\text { sou atendido }\end{array}$ & 0,00 & 14,50 & 4,30 & 46,40 & 26,10 & 8,70 & 69 & 100,00 \\
\hline $\begin{array}{lr}\text { Os atendentes } & \text { são } \\
\text { devidamente } & \\
\text { uniformizados } & \text { e } \\
\text { identificados } & \end{array}$ & 0,00 & 2,80 & 0,00 & 63,40 & 32,40 & 1,40 & 71 & 100,00 \\
\hline
\end{tabular}




\begin{tabular}{|l|l|l|l|l|l|l|l|l|}
\hline $\begin{array}{l}\text { Os atendentes são } \\
\text { cordiais } \\
\text { atenciosos }\end{array}$ & 0,00 & 2,80 & 2,80 & 62,00 & 31,00 & 1,40 & 71 & 100,00 \\
\hline
\end{tabular}

Quadro 7 - Avaliação dos serviços prestados pela central de monitoramento, por sentenças. Fonte: Dados do Questionário (2011).

Ao serem questionados sobre o comportamento da equipe da central de monitoramento, aproximadamente $95 \%$ dos respondentes afirmaram que as operadoras foram cordiais e atenciosas.

Por outro lado, $18,8 \%$ dos clientes revelaram que nem sempre foram atendidos quando solicitaram visitas dos atendentes em sua residência ou estabelecimento. Percebeu-se ainda a existência de uma parcela de clientes que alega que tiveram dúvidas que não foram sanadas - o que representa $15,5 \%$. Os clientes foram questionados ainda quanto à agilidade no atendimento prestado pelos atendentes e cerca de 14,3\% afirmaram que não foram atendidos de forma ágil.

Las Casas (2008) aponta que os serviços têm três características: a intangibilidade, a inseparabilidade e a heterogeneidade. Para a primeira característica, o autor mostra que os serviços são abstratos, sendo necessários um tratamento especial para validar a comparação entre serviços com a mesma atividade de mercado.

A segunda característica, apontada por Las Casas (2008) refere-se a incapacidade de estocar serviços, visto que não são mensuráveis. E a heterogeneidade refere se a incapacidade de manter a qualidade do serviço de maneira constante. Alguns índices comprovados no Quadro 7, mostram que alguns itens do atendimento de fato causam descontentamento ao cliente. O autor indica, ainda, que este fato ocorre por causa dos serviços serem produzidos pelo ser humano, que tem sua natureza instável e que nesta condição a qualidade da produção também será instável.

\subsubsection{Administrativo Financeiro}

Conforme apresenta o Quadro 8, quanto aos serviços prestados pelos colaboradores do setor administrativo, mais de $85 \%$ dos clientes se mostraram satisfeitos quanto ao prazo oferecido para pagamento da fatura dos serviços. Ainda $92,8 \%$ dos respondentes alegaram que receberam suas faturas livres de erros. Este alto índice mostra a seriedade com que são tratados os assuntos referentes à cobrança dos serviços, o que diminui significativamente a possibilidade de erros com cobranças indevidas. 
Questionados ainda quanto às formas de pagamento oferecidas pela empresa percebe-se que $80,9 \%$ afirmam que não gostariam de ter suas faturas debitadas em conta corrente. Outros clientes revelaram ainda seu descontentamento com os preços cobrados pelos produtos que a empresa em estudo oferece; estes clientes somam $27,1 \%$. Uma parcela dos respondentes $(20,0 \%)$ afirmou que pagaram caro pelos serviços que a empresa oferece. Ou seja, pode-se perceber uma parcela de clientes descontente com os preços cobrados pela empresa, fato que este que pode reduzir a possibilidade de novas vendas (Diário de Pesquisa, 2011).

\begin{tabular}{|c|c|c|c|c|c|c|c|c|}
\hline & \begin{tabular}{|c|} 
DISCORDO \\
TOTALMENTE
\end{tabular} & DISCORDO & INDECISO & CONCORDO & $\begin{array}{l}\text { CONCORDO } \\
\text { TOTALMENTE }\end{array}$ & $\begin{array}{l}\text { NÃO SEI, } \\
\text { NUNCA } \\
\text { UTILIZEI }\end{array}$ & TOTAL & $\%$ \\
\hline & $\%$ & $\%$ & $\%$ & $\%$ & $\%$ & $\%$ & & \\
\hline 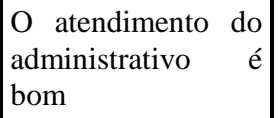 & 0,00 & 2,90 & 7,10 & 50,00 & 20,00 & 20,00 & 70 & 100,00 \\
\hline$\left|\begin{array}{lrr}\text { A } & \text { JM } & \text { oferece } \\
\text { serviços } & \text { que } & \text { valem } \\
\text { o que pago } & \text { por eles }\end{array}\right|$ & 0,00 & 5,70 & 14,30 & 55,70 & 20,00 & 4,30 & 70 & 100,00 \\
\hline $\begin{array}{l}\text { As faturas chegam } \\
\text { corretamente }\end{array}$ & 0,00 & 1,40 & 1,40 & 69,60 & 23,20 & 4,30 & 69 & 99,90 \\
\hline $\mid \begin{array}{l}\mathrm{O} \text { preço dos } \\
\text { produtos é bom }\end{array}$ & 1,40 & 8,60 & 17,10 & 50,00 & 20,00 & 2,90 & 70 & 100,00 \\
\hline $\begin{array}{lll}\text { Tenho certeza } & \text { de } \\
\text { que pago por } & \text { um } \\
\text { serviço } & \text { de } \\
\text { qualidade } & \\
\end{array}$ & 0,00 & 7,20 & 7,20 & 53,60 & 29,00 & 2,90 & 69 & 99,90 \\
\hline $\begin{array}{l}\text { O dia de pagamento } \\
\text { da minha fatura é } \\
\text { bom }\end{array}$ & 1,50 & 4,40 & 4,40 & 61,80 & 23,50 & 4,40 & 68 & 100,00 \\
\hline $\begin{array}{|lrr|}\text { Gostaria } & \text { de } & \text { ter } \\
\text { minha } & \text { fatura } \\
\text { debitada } & \text { em } & \text { conta } \\
\text { corrente } & & \\
\end{array}$ & 14,70 & 54,40 & 11,80 & 10,30 & 5,90 & 2,90 & 68 & 100,00 \\
\hline 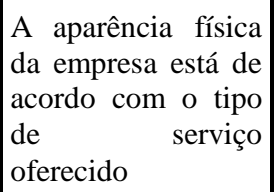 & 0,00 & 2,90 & 2,90 & 56,50 & 31,90 & 8,70 & 69 & 100,00 \\
\hline $\begin{array}{l}\text { Os equipamentos e } \\
\text { móveis da empresa } \\
\text { são modernos e } \\
\text { conservados }\end{array}$ & 1,40 & 7,10 & 7,10 & 47,10 & 21,40 & 20,00 & 70 & 99,90 \\
\hline
\end{tabular}

Quadro 8 - Avaliação dos serviços prestados pela área administrativo-financeira, por sentenças.

Revista de Gestão e Secretariado - GeSec, São Paulo, v. 4, n. 2, p 151-176, jul./dez. 2013. 
Fonte: Dados do Questionário (2011).

\subsubsection{5 Área Técnica}

Ao se considerar o serviço prestado pela equipe técnica, conforme Quadro 9, percebe-se que cerca de $95 \%$ dos respondentes reconheceram que os técnicos apresentaram-se devidamente identificados e uniformizados e ainda souberam comportar-se profissionalmente.

\begin{tabular}{|l|c|c|c|c|c|c|c|c|}
\hline & $\begin{array}{c}\text { DISCORDO } \\
\text { TOTALMENTE }\end{array}$ & DISCORDO & INDECISO & CONCORDO & $\begin{array}{c}\text { CONCORDO } \\
\text { TOTALMENTE }\end{array}$ & $\begin{array}{c}\text { NÃO SEI, } \\
\text { NUNCA } \\
\text { UTILIZI }\end{array}$ & TOTAL & \% \\
\hline $\begin{array}{l}\text { O atendimento dos } \\
\text { técnicos é bom }\end{array}$ & 1,40 & 2,80 & 2,80 & 54,90 & 38,00 & 0,00 & 71 & 99,90 \\
\hline $\begin{array}{l}\text { Os técnicos estão } \\
\text { devidamente } \\
\text { uniformizados e } \\
\text { identificados }\end{array}$ & 0,00 & 0,00 & 4,20 & 53,50 & 42,30 & 0,00 & 71 & 100,00 \\
\hline $\begin{array}{l}\text { Os materiais } \\
\text { utilizados pelos } \\
\text { técnicos são de boa } \\
\text { qualidade }\end{array}$ & 0,00 & 1,40 & 11,30 & 52,10 & 32,40 & 2,80 & 71 & 100,00 \\
\hline $\begin{array}{l}\text { Os técnicos } \\
\text { possuem } \\
\text { comportamento } \\
\text { profissional }\end{array}$ & 0,00 & 1,40 & 2,80 & 56,30 & 39,40 & 0,00 & 71 & 99,90 \\
\hline $\begin{array}{l}\text { Os problemas } \\
\text { técnicos que } \\
\text { ocorrem no sistema } \\
\text { de alarme são } \\
\text { resolvidos }\end{array}$ & 1,40 & 4,20 & 8,50 & 50,70 & 32,40 & 2,80 & 71 & 100,00 \\
\hline $\begin{array}{l}\text { Os técnicos } \\
\text { possuem } \\
\text { ferramentas } \\
\text { adequadas para a } \\
\text { realização dos } \\
\text { serviços }\end{array}$ & 0,00 & 4,30 & 10,00 & 50,00 & 31,40 & 4,30 & 70 & 100,00 \\
\hline
\end{tabular}

Revista de Gestão e Secretariado - GeSec, São Paulo, v. 4, n. 2, p 151-176, jul./dez. 2013. 


\begin{tabular}{|c|c|c|c|c|c|c|c|c|}
\hline $\mid \begin{array}{l}\text { Os } \quad \text { técnicos } \\
\text { possuem } \\
\text { conhecimento sobre } \\
\text { os produtos }\end{array}$ & 0,00 & 4,20 & 7,00 & 53,50 & 29,60 & 5,60 & 71 & 99,90 \\
\hline $\begin{array}{l}\text { As manutenç̃̃es e } \\
\text { reparos apresentam } \\
\text { problemas } \\
\text { posteriores }\end{array}$ & 5,80 & 29,00 & 10,10 & 43,50 & 11,60 & 0,00 & 69 & 100,00 \\
\hline$\left|\begin{array}{lr}\text { Ao término } & \text { da } \\
\text { instalação, } & \text { o } \\
\text { técnico deixa } & 0 \\
\text { ambiente limpo } & \text { e } \\
\text { organizado } & \end{array}\right|$ & 2,80 & 7,00 & 2,80 & 62,00 & 23,90 & 1,40 & 71 & 99,90 \\
\hline $\begin{array}{l}\text { Quando solicito um } \\
\text { reparo no sistema, } \\
\text { sou rapidamente } \\
\text { atendido }\end{array}$ & 1,40 & 15,70 & 7,10 & 52,90 & 21,40 & 1,40 & 70 & 99,90 \\
\hline
\end{tabular}

Quadro 9 - avaliação dos serviços prestados pela área técnica, por sentenças.

Fonte: Dados do Questionário (2011).

Os clientes ainda manifestaram sua satisfação quanto ao atendimento oferecido pelos técnicos, comprovado pelo índice de 92,9\%. Por outro lado, grande parte dos respondentes (aproximadamente 45\%) revelaram insatisfação principalmente em se tratando dos problemas que ocorreram no sistema de alarme após a manutenção realizada pela equipe técnica. Verificou-se que a equipe técnica não consegue de fato solucionar os problemas que ocorrem no sistema de alarme, que revela a necessidade de um consultor técnico para fazer essa verificação junto aos clientes (Diário de Campo, 2011).

Finalmente $24 \%$ dos respondentes afirmaram que quando solicitaram algum reparo houve um tempo longo de espera até a realização do serviço solicitado - o que demonstrou que o quadro funcional não consegue atender aos clientes em tempo hábil.

\section{CONSIDERAÇÕES FINAIS}

O principal objetivo do estudo foi identificar a percepção dos clientes quanto à qualidade do atendimento prestado pelos funcionários, tomando por base os produtos e serviços oferecidos pela empresa. Com o apoio do referencial teórico foi possível construir um arcabouço de conhecimentos referentes à qualidade e satisfação no atendimento.

Os resultados obtidos foram válidos de modo que demonstraram que a maior parte dos clientes pesquisados mostrou-se relativamente satisfeita com os serviços prestados. Percebeu-se que a maior satisfação esteve relacionada com a qualidade dos produtos e a padronização dos

Revista de Gestão e Secretariado - GeSec, São Paulo, v. 4, n. 2, p 151-176, jul./dez. 2013. 
serviços oferecidos pela empresa. Constatou-se ainda um elevado nível de satisfação com relação ao atendimento prestado pela equipe da central de monitoramento, no qual, dentre outras coisas, se destacou a cordialidade e a agilidade dos serviços. Nota-se que todos os índices desse setor estão muito próximos a atingir o percentual máximo de satisfação.

Evidenciou-se na pesquisa que os menores índices de satisfação estão relacionados com a equipe de vendas, sendo que os clientes mencionaram existir algum descuido por parte dos vendedores em certos aspectos. Dentre os pontos questionados quanto ao setor, revelaram-se o prazo estipulado para a entrega dos produtos, que em vários casos excederam ao tempo combinado durante a negociação bem como o atendimento oferecido por eles. Percebeu-se ainda uma parcela de clientes insatisfeita com a equipe técnica, pelo fato de ela ser composta por um baixo número de colaboradores, o que, consequentemente, resulta certa demora para a efetuação de reparos nos sistemas de segurança dos clientes.

Os principais resultados da pesquisa indicaram a necessidade da implantação de ações de melhoria nos setores que apresentaram os menores índices de satisfação dos clientes. Para uma empresa atingir um nível de qualidade considerável, todos os setores da empresa devem estar preparados para satisfazer as necessidades dos clientes com excelência. É possível afirmar que, independentemente do ramo de atuação da empresa, é imprescindível que ela esteja sempre em busca de atingir o maior número de clientes satisfeitos, uma vez que permanecem atuantes no mercado apenas as empresas que proporcionam ao cliente o atendimento de qualidade.

Percebe-se ainda, que diante da colaboração dos gestores e a participação dos clientes pesquisados quanto à realização deste trabalho, pontua-se positivamente para a inclusão de um profissional de secretariado executivo para atuar como gestor da qualidade no atendimento. Tal profissional poderia trazer aos gestores da empresa novos conhecimentos quanto ao tema pesquisado, uma vez que a abrangência de assuntos trabalhados durante ao decorrer da graduação é grande, podendo posteriormente aplicá-los ao cotidiano da empresa e assim elevar o nível da qualidade da JM Alarmes.

\section{REFERENCIAS}


Cobra, M. (2009). Administração de vendas (4a ed.). São Paulo: Atlas.

Denton, D. K. (2008). Qualidade em serviços: o atendimento ao cliente como fator de vantagem competitiva. São Paulo: Makron.

Di Serio, L. C \& Vasconcelos,, M. A. de. (2009). Estratégia e competitividade empresarial: inovação e criação de valor. São Paulo: Saraiva.

Gianesi, I. G. N. \& Corrêa, H. L. (2008). Administração estratégica de serviços: operações para a satisfação do cliente. São Paulo: Atlas.

Gil, A. C. (2006). Como elaborar projetos de pesquisa. São Paulo: Atlas.

Godoy, A. S. (1995). Introdução à pesquisa qualitativa e suas possibilidades. Revista de Administração de Empresas (Vol. 35, n. 2, pp. 57-63), São Paulo, mar./abr.

Hargreaves, L.; Zuanetti, R. \& LEE, R. (2011). Qualidade em prestação de serviços. Rio de Janeiro: Senac.

Hooley, G. J. \& Saunders, J. (2006). Posicionamento competitivo: como estabelecer e manter uma estratégia de marketing no mercado. São Paulo: Makron Books.

Johnston, R. \& Clark, G. (2007). Administração de operações de serviço. São Paulo: Atlas.

Kotler, P. (1998). Administração de marketing. São Paulo: Pearson.

Kotler, P. \& Armstrong, G. (2007). Princípios de Marketing. São Paulo: Prentice Hall.

Las Casas, A. L. (2009). Marketing de serviços. São Paulo: Atlas. . (2008). Qualidade total em serviços. São Paulo: Atlas.

Levy, M. \& Weitz, B. A. (2000). Administração de varejo. São Paulo: Atlas.

Lima, M. C. (2008). Monografia: a engenharia da produção acadêmica (2a ed. rev.). São Paulo: Saraiva.

Mirshawka, V. (1993). Criando valor para o cliente. São Paulo: Makron Books.

Nonato Junior, R. (2009). Epistemologia e teoria do conhecimento em secretariado executivo: a fundação das ciências da assessoria. Fortaleza: Expressão Gráfica. 
Silva, F. G. da \& Zambon, M. S. (2006). Gestão do relacionamento com o cliente. São Paulo: Thomson.

Townsend, P. L. (2010). Compromisso com a qualidade. Rio de Janeiro: Campus.

Urdan, F. T. \& Urdan, A. T. (2006) Gestão do composto de marketing. São Paulo: Atlas.

Zeithaml, V. A. \& Bitner, M. J. (2007) Marketing de serviços: a empresa com foco no cliente. Porto Alegre: Bookman.

Revista de Gestão e Secretariado - GeSec, São Paulo, v. 4, n. 2, p 151-176, jul./dez. 2013. 